\title{
In Vivo Measurements of Changes in Respiratory Mechanics with Age in Mice Deficient in Surfactant Protein D
}

\author{
RACHEL A. COLLINS, MACHIKO IKEGAMI, THOMAS R. KORFHAGEN, \\ JEFFREY A. WHITSETT, AND PETER D. SLY
}

\begin{abstract}
Division of Clinical Sciences, Telethon Institute for Child Health Research, Perth, Western Australia [R.A.C., P.D.S.]; Division of Pulmonary Biology, Children's Hospital Medical Center, Cincinnati, Ohio, U.S.A. [M.I., T.R.K. , J.A.W.]; Centre for Child Health Research, University of Western Australia, Perth, Western Australia [R.A.C., P.D.S.]
\end{abstract}

\begin{abstract}
Mice deficient in surfactant protein D [SP-D (-/-)] develop progressive emphysema with age, associated with loss of parenchymal tissue, subpleural fibrosis, and accumulation of abnormal elastin fibers. We measured the changes in lung function, partitioned into components for the airways and lung parenchyma, occurring with age in SP-D $(-/-)$ mice at three ages $(n=8$ per group) $(5,8$, and $13 \mathrm{wk})$. Impedance spectra between 0.25 and $19.625 \mathrm{~Hz}$ were calculated and a model, consisting of an airway compartment [airway resistance (Raw) and inertance (Iaw)] and a constant-phase tissue compartment [coefficients of tissue damping $(\mathrm{G})$ and elastance $(\mathrm{H})]$, was fitted to the data. Hysteresivity was calculated as $\mathrm{G} / \mathrm{H}$. Adult values of Raw, $\mathrm{G}$, and $\mathrm{H}$ are reached by 8 wk of age in wild-type controls. Raw and $\mathrm{H}$ were lower at all ages in SP-D $(-/-)$ compared with the wild-type controls ( $p=0.006$ and 0.029 , respectively), and a similar trend was seen in $\mathrm{G}(p=0.060)$. The patterns of change in respiratory mechanics were similar in both SP-D $(+/+)$ and $(-/-)$ groups.
\end{abstract}

\section{ABSTRACT}

There were no changes in hysteresivity with age and no differences between wild-type and SP-D $(-/-)$ mice. These data demonstrate that the changes in lung structure in SP-D $(-/-)$ mice are reflected in the mechanical properties of both airway and lung parenchyma measured in vivo. (Pediatr Res 53: 463467, 2003)
SP-D, surfactant protein D
FOT, forced oscillation technique
Zrs, respiratory input impedance
Raw, airway resistance
Iaw, airway inertance
G, coefficient of tissue damping
H, coefficient of tissue elastance
$\boldsymbol{\eta}$, hysteresivity

\section{Abbreviations}

There are four surfactant-associated proteins and all are thought to be important for normal lung function, including surface tension-lowering properties, host defense, and normal lung growth and development. Mice deficient in SP-D [SP-D $(-/-)]$ develop abnormal lung architecture with age, characterized by severe progressive emphysema associated with subpleural fibrosis and abnormal elastin deposition (1). SP-D is a $43 \mathrm{kD}$ member of the collectin family of proteins, and is expressed in type-II alveolar cells (2) in the lungs, as well as in various tissues, including the mouse heart, stomach, and kidney (3). SP-D plays a role in host defense, and is also thought

Received May 8, 2002; accepted October 4, 2002.

Correspondence: Peter D. Sly, Telethon Institute for Child Health Research, PO Box 855, West Perth, Western Australia, 6872; e-mail: peters@ichr.uwa.edu.au

Supported by the National Health and Medical Research Council, Canberra, Australia (grant 961278), and the National Institutes of Health, Bethesda, MD, U.S.A. (grants HL63329 and HL61646).

DOI: 10.1203/01.PDR.0000049464.46191.BF to influence macrophage function and signaling via collectin receptors present on target cells (4). SP-D (-/-) mice also display abnormal surfactant morphology and increased levels of tissue and alveolar surfactant (5), however, surfactant function appears to be normal in the absence of SP-D. Minimum surface tension and equilibrium surface tension in surfactant isolated from SP-D $(-/-)$ mice is normal and similar to wild-type mice (6), suggesting that the SP-D protein is not essential for the maintenance of normal surfactant surface activity.

Analysis of pressure-volume curves from SP-D (-/-) mice (1) showed increased lung volumes in SP-D (-/-) mice at 12 wk compared with wild-type mice. These increased lung volumes are consistent with histologic and morphometric studies demonstrating emphysema (1). Increased lung volumes are not evident in SP-D (-/-) mice until 3 wk of age, suggesting that the major consequences of SP-D deficiency are in abnormal 
alveolar remodeling rather than in abnormal alveolar development.

To date, measurement of lung function in SP-D (-/-) mice has only been studied using pressure-volume curves in vitro, and no assessment has been made of airway or lung parenchymal mechanics. FOT and fitting the constant phase model (7) to the resulting impedance spectra is a highly effective means of partitioning lung function into components representing the mechanical properties of both airways and lung parenchyma in vivo (8), and was used in the present study to detect changes in lung function in SP-D $(-/-)$ mice with advancing age. Using this approach, we are able to describe Raw, representing the Newtonian resistance of airway, related to flow of gas through the airway, together with a small component from chest wall resistance. In addition, the coefficients of tissue damping $(\mathrm{G})$ and elastance $(\mathrm{H})$ represent the energy expended in moving the lung tissues during the application of the small amplitude oscillation signals used to measure FOT. Assessment of the lung function changes with age in SP-D $(-/-)$ mice is expected to provide insight into how changes in lung structure and surfactant can affect lung function.

\section{METHODS}

National Institutes of Health Swiss black SP-D $(+/+)$ and SP-D $(-/-)$ mice, generated by targeted gene inactivation as recently described (5), were transported from Cincinnati, $\mathrm{OH}$, U.S.A., to Perth, Australia, for lung function testing. At least 1 wk was allowed for acclimatization. Experimental procedures were approved by the animal ethics committee of the Institute for Child Health Research and conformed to the guidelines of the National Health and Medical Research Council of Australia.

Animal preparation. Mice were housed in a clean animal house under pathogen-free conditions and allowed food and water ad libitum. Eight SP-D (-/-) and 8 SP-D $(+/+)$ control mice were included in each of three age groups, namely 5,8 , and $13 \mathrm{wk}$. Anesthesia was induced by intraperitoneal injection of $0.1 \mathrm{~mL} / 10 \mathrm{~g}$ mouse body weight of a ketamine-xylazinesaline mixture [4:1:5; ketamine $40 \mathrm{mg} / \mathrm{mL}$ (Parnell Laboratories, NSW, Sydney, Australia), xylazine $2.0 \mathrm{mg} / \mathrm{mL}$ (Bayer Australia, Pymble, NSW, Sydney, Australia)]. Two thirds of the dose was given to induce anesthesia, with the remaining dose given when the animal was attached to the ventilator. Muscle relaxants were not used during the study.

Once surgical anesthesia was established, a tracheostomy was performed and a polyethylene cannula $(1.0 \mathrm{~cm}$, internal diameter $0.081 \mathrm{~cm}$ ) was inserted in the distal trachea. Mice were ventilated with a tidal volume of $8 \mathrm{~mL} / \mathrm{kg}$ at a rate of 450 breaths per minute and a positive end-expiratory pressure of 2 $\mathrm{hPa}$, using a custom-designed ventilator (flexiVent, Scireq, Montreal, Canada). This rate is somewhat above the spontaneous breathing rate (300-400 bpm) of the mice and was used to ensure that mice did not breathe during the pauses in ventilation during which lung function was measured (see below). The special features of this ventilator include a precision, computer-controlled piston that is capable of accurately producing any desired waveform; accurate measurements of de- livered volume (and thus flow) by tracking the piston movement (with appropriate corrections for gas compression); and the ability to accurately deliver the small tidal volumes required for ventilating mice.

Measurement of lung mechanics. Lung function was measured using a modification of the low-frequency FOT (8). Zrs was measured between 0.25 and $19.625 \mathrm{~Hz}$ by applying a composite signal (16 s long) containing 19 mutually prime sinusoidal waves during pauses in regular ventilation. Peak-topeak amplitude was small $(\approx 10 \%)$ compared with the tidal volume. Data were rejected if the coherence values were $<0.95$. The flexiVent ventilator was used both for regular ventilation and for delivery of the oscillatory signal without the need to disturb the mice. The constant-phase model described by Hantos et al. (7) was used to partition Zrs into components representing the mechanical properties of the airways and parenchyma. This model consists of a frequency-independent Raw and Iaw and a constant-phase tissue component $[(\mathrm{G}-$ $\mathrm{jH}) / \omega^{\alpha}$, where $\mathrm{G}$ and $\mathrm{H}$ are coefficients for tissue damping and elastance, respectively, $\omega$ is angular frequency, and $\alpha$ determines the frequency dependence of the real and imaginary parts of the impedance]. Hysteresivity describes the mechanical coupling between tissue damping and elastance (9) and is calculated as $\eta=\mathrm{G} / \mathrm{H}$.

The calibration procedure removes the mechanical impedance of the tracheal cannula. This procedure has been described in detail elsewhere $(10,11)$. Briefly, a dynamic calibration, including the tracheal cannula, is performed by recording the pressure and volume displacement of the flexiVent piston while oscillating the piston with the tracheal cannula blocked (closed calibration) and again with the cannula open to atmosphere (open calibration). These calibration signals allow the physical properties of the flexiVent itself (gas compression within the cylinder and flow resistance through the connecting tubing, including the tracheal cannula) to be removed from the measurements of Zrs. Data reported in this article represent the mechanical properties of the mice alone. Iaw is negligible in mice, especially as the inertance of the tracheal cannula has been removed, and has not been reported.

After surgical preparation, mice were attached to the ventilator and allowed to stabilize for $5 \mathrm{~min}$. Five measurements of Zrs were then performed at 1-min intervals at end-expiration, with a positive pressure of $2 \mathrm{hPa}$. A 1-s pause was allowed before each measurement, to ensure dynamic hyperinflation did not interfere with the measurements. The parameters obtained from the constant-phase model were averaged and reported. Figure 1 shows a representative impedance spectrum and the fit from the constant phase model from one SP-D $(+/+)$ and one $(-/-)$ at ages 5,8 , and 13 wk (adult).

Statistical analysis. Differences between SP-D $(+/+)$ and SP-D (-/-) were analyzed by two-way ANOVA (SigmaStat, version 2.0, Jandel Scientific, Middle Cove, NSW, Australia). Differences between ages and between groups [control versus SP-D $(-/-)]$ were further tested by the Tukey multiple comparison test procedure. All data are presented as mean \pm SE. Statistical significance was accepted at the $5 \%$ level. 


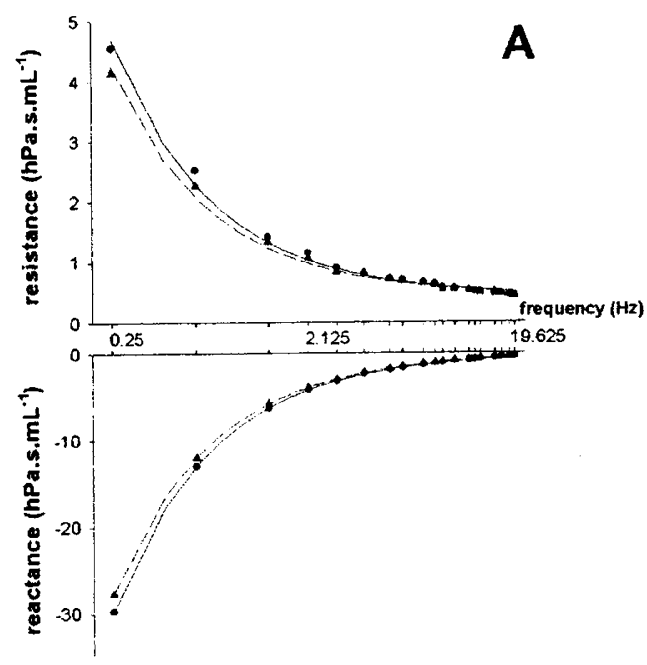

\section{RESULTS}

No differences were seen in weight between the genotypes (two-way ANOVA). The weights for the SP-D $(+/+)$ and $(-/-)$ were $17.1 \pm 0.35 \mathrm{~g}$ versus $18.6 \pm 0.42 \mathrm{~g}$ at $5 \mathrm{wk}(p=$ $0.028) ; 21.0 \pm 1.09 \mathrm{~g}$ versus $19.8 \pm 0.82 \mathrm{~g}$ at $8 \mathrm{wk}(p=$ $0.039)$, and $25.3 \pm 1.80 \mathrm{~g}$ versus $27.3 \pm 0.70 \mathrm{~g}$ in the adult group $(p=0.17)$.

In SP-D $(+/+)$ animals, Raw showed a progressive decline with age, from $0.51 \pm 0.03 \mathrm{hPa} / \mathrm{s} / \mathrm{mL}$ at 5 wk of age to $0.43 \pm$ $0.01 \mathrm{hPa} / \mathrm{s} / \mathrm{mL}$ at 8 wk of age and $0.40 \pm 0.02 \mathrm{hPa} / \mathrm{s} / \mathrm{mL}$ in adults (Fig. $2 A$ ). This fall was statistically significant (ANOVA $F=23.85, p<0.001$ ), with Raw in 5-wk-old animals being significantly greater than that in 8-wk olds, (Tukey test, $q=$ $3.92, p=0.022)$ and in adults $(q=5.53, p=0.001)$. Raw was not different between the 8-wk-old mice and adult mice $(q=$ $1.67, p=0.47)$. Similar falls were seen in the parameters of parenchymal mechanics. G fell from $7.78 \pm 0.45 \mathrm{hPa} / \mathrm{mL}$ at 5

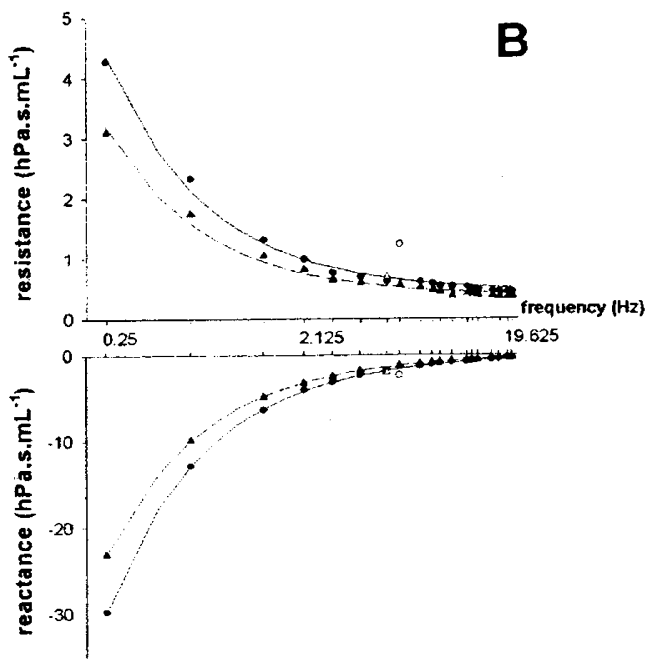
wk to $5.38 \pm 0.42 \mathrm{hPa} / \mathrm{mL}$ at 8 wk and $5.63 \pm 0.42 \mathrm{hPa} / \mathrm{mL}$ in adult mice $(F=17.98, p<0.001)$ Fig. $2 B)$. $\mathrm{G}$ in 5 -wk olds was significantly greater than $\mathrm{G}$ in 8-wk olds $(q=4.98, p=$ $0.003)$ and adults $(q=5.20, p=0.002)$. Similarly, $\mathrm{H}$ fell from $61.87 \pm 3.62 \mathrm{hPa} / \mathrm{mL}$ at $5 \mathrm{wk}$ to $42.89 \pm 3.39 \mathrm{hPa} / \mathrm{mL}$ at $8 \mathrm{wk}$ and $44.35 \pm 3.39 \mathrm{hPa} / \mathrm{mL}$ in adults $(F=17.10, p<0.001)$ (Fig. $2 C$ ). Again, the values from 5 -wk olds were significantly different from the 8-wk olds $(q=5.4, p=0.001)$ and adults $(q=5.00, p=0.003)$.

Similar changes with age were seen in the SP-D $(-/-)$ mice $(F=23.29, p<0.001 ; F=17.98, p<0.001$; and $F=17.10$, $p<0.001$ for Raw, $\mathrm{G}$, and $\mathrm{H}$, respectively) (Fig. 2). In
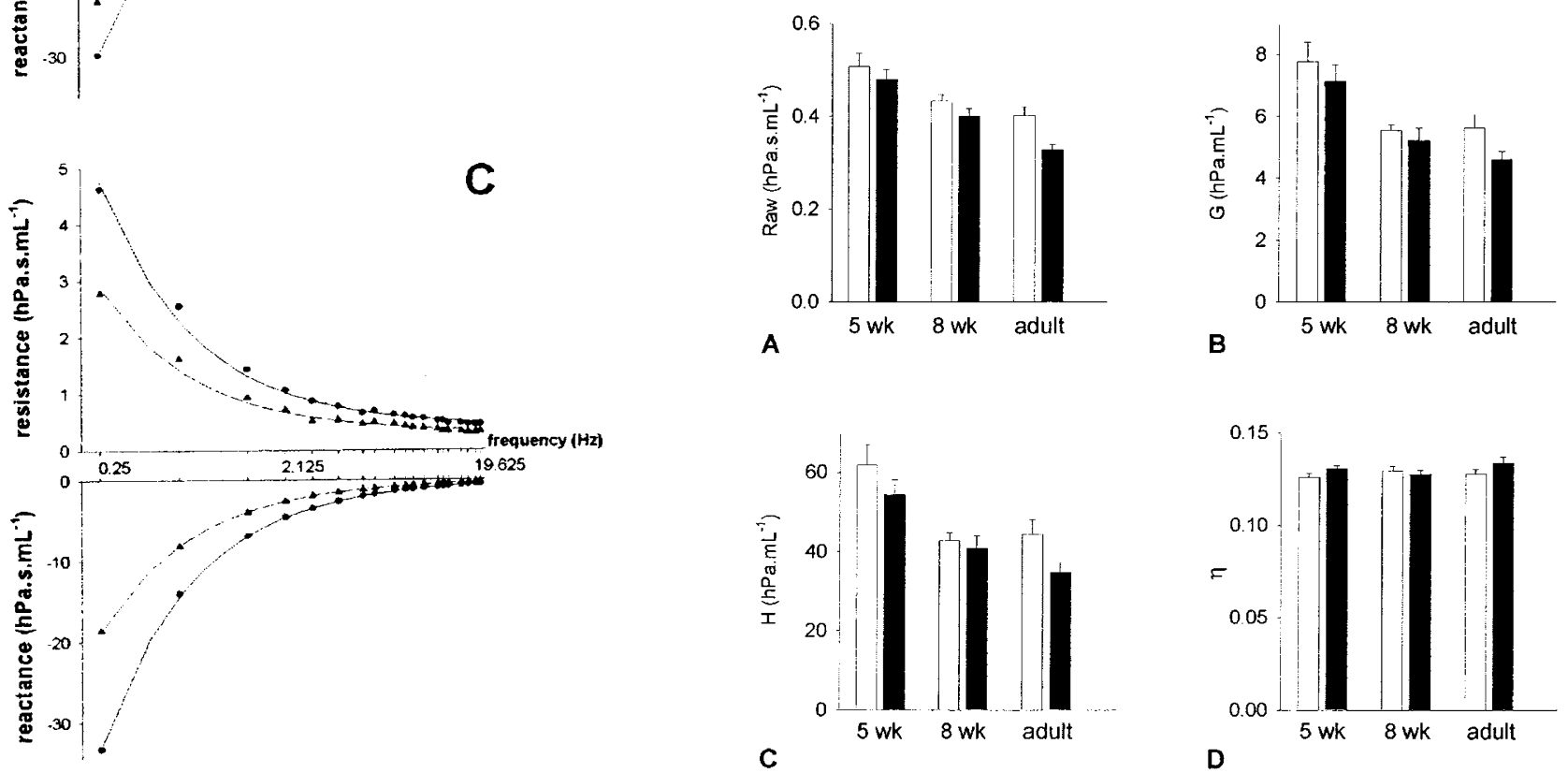

Figure 1. Impedance spectrum (Zrs) together with the model fit from the constant phase model. Measured data are shown as dots and the model fit as a solid line. Data are shown from representative SP-D $(+/+)$ (closed circles, solid lines) and $(-/-)$ (closed triangles, dashed lines) animals at $5 \mathrm{wk}(A)$ and $8 \mathrm{wk}(B)$, and in adults $(C)$. Open symbols represent data points corrupted by cardiac frequencies or their harmonics, which were omitted from the model fits. The resistive component is shown by the upper curves and the reactance shown by the lower curves.

Figure 2. Lung function in SP-D $(-/-)$ and SP-D $(+/+)$ mice, showing $(A)$ Raw; $(B) \mathrm{G}$; $(C) \mathrm{H}$; and $(D) \eta$. Data from SP-D $(+/+)$ animals are shown by the open bars and data from the SP-D $(-/-)$ animals are shown by the filled bars. Data are presented as group mean and SEM. Statistical analysis by two-way ANOVA shows significant falls in Raw, $\mathrm{G}$, and $\mathrm{H}$ with age in both groups and significant differences between the groups in Raw and $\mathrm{H}$, with a similar trend in $\mathrm{G}$ that did not reach statistical significance $(p=0.06)$. See text for further details. 
addition, Raw was significantly lower in the adult mice $(0.33 \pm$ $0.019 \mathrm{hPa} / \mathrm{s} / \mathrm{mL})$ than at $8 \mathrm{wk}$ of age $(0.40 \pm 0.019 \mathrm{hPa} / \mathrm{s} / \mathrm{mL}$, $q=3.88, p=0.024)$. The two-way ANOVA showed statistically significantly lower values of $\operatorname{Raw}(F=8.48, p=0.006)$ and of $\mathrm{H}(F=5.12, p=0.029)$ in SP-D $(-/-)$ mice when compared with SP-D $(+/+)$ mice. A similar trend was seen for $\mathrm{G}(F=3.74, p=0.060)$, but this did not reach statistical significance.

There were no significant changes in hysteresivity with age in either group or differences between the control and SP-D $(-/-)$ mice (Fig. 2D).

\section{DISCUSSION}

Measurement of lung function in SP-D $(-/-)$ mice by FOT revealed significant differences between SP-D $(+/+)$ and SP-D $(-/-)$ mice in both the airway $(\mathrm{R})$ and tissue $(\mathrm{H})$ components of respiratory mechanics, but no differences in hysteresivity between the groups. Previous histologic and morphometric studies have shown enlarged airspaces starting as young as 3 wk of age and progressing to development of emphysema and fibrosis in adult life. In addition, the lungs of SP-D $(-/-)$ mice contain abnormal regions of parenchyma consisting of thick, highly coiled elastic fibers (1). These changes in lung structure, together with the normal surface tension-lowering properties of surfactant (6) in these mice, are likely to explain these changes in lung function.

The decreased Raw observed in the present study in SP-D $(-/-)$ mice, over and above the normal decrease in Raw with age seen in the SP-D $(+/+)$ mice, could result from the increased lung volumes reported in SP-D $(-/-)$ mice (1), especially if the normal mechanical interdependence (i.e. the parenchymal pull on the airways) between parenchyma and airways is preserved in the early stages of development of emphysema in these animals. Measurements were made at end-expiration with a positive expiratory pressure of $2 \mathrm{hPa}$. As the lungs of the SP-D (-/-) mice are more distensible than their wild-type controls, this could have translated into measurements being made at higher lung volumes in the SP-D $(-/-)$ mice.

The changes reported in the mechanical properties of the lung parenchyma are, perhaps, more easily understood. The enlarged airspaces, seen as early as $3 \mathrm{wk}$ of age, are likely to result in decreased elastic recoil of the lungs, i.e. a decrease in the elastic properties of the lung parenchyma. Emphysema results in an increase in airspace in the lung secondary to tissue destruction and a reduction in the amount of lung parenchyma. The decrease in $\mathrm{G}$ and $\mathrm{H}$, seen in SP-D (-/-) mice, is also consistent with a decrease in lung parenchymal mass.

The data presented here may shed some light onto the relative contributions of tissue forces and surface forces to what is measured as lung parenchymal mechanics in vivo. The mechanical properties of the lung parenchyma are determined partly by a tension skeleton made up of connective tissue fibers that spread throughout the lung in an organized fashion, and partly by surface-acting forces (12). The tension skeleton consists of 1) axial fibers that fan out centrifugally from the hilum along the branching airway tree; 2) peripheral fibers that originate in the pleura and penetrate centripetally into the lung; and 3) alveolar septal fibers that join the two (12). The pulmonary interstitium contains myofibroblasts that contain actin and myosin microfilaments of the smooth muscle type, collagen and elastin fibers, and some free extracellular fluid related to lymph. From a mechanical point of view, the collagen and elastin fibers are intimately associated and cannot really be considered to be separate (12). Fredberg and Stamenovic (9) recognized this phenomenon in proposing the Structural Damping Paradigm, in which they proposed that the dissipative properties of lung tissue (tissue damping or frequencydependant tissue resistance) and the elastic properties were coupled and could be expressed as hysteresivity and represented by the Greek letter eta $(\eta)$. Eta has been shown to be relatively constant across species and under a variety of experimental circumstances, although $\eta$ has been shown to increase in response to constrictor agonists both in vivo and in vitro (13-16).

When measurements are made in vivo, the surface-acting forces are also likely to contribute to the parenchymal mechanics. As lung volume decreases, the radius of curvature of alveoli increases, resulting in an increased surface tension and tendency for the alveoli to collapse. Surfactant reduces surface tension and minimizes the tendency for alveoli to collapse. Indeed, mice with a deficiency of surfactant protein $\mathrm{C}$ show alveolar instability and a decreased viscoelasticity at low lung volumes (17). Prematurely born infants and animals that are deficient in surfactant have stiff lungs. Their lungs become much more compliant after surfactant replacement. Although the majority of this change is likely to be the result of alveolar recruitment, surfactant also appears to contribute to the distensibility (i.e. compliance) of the lungs (18).

In the present study, we report changes in tissue mechanics, i.e. a significant decrease in $\mathrm{H}$ and a decrease in $\mathrm{G}$ that approaches significance, with no changes in $\eta$ in SP-D $(-/-)$ mice when compared with their wild-type controls. These mice develop progressive emphysema with age associated with loss of parenchymal tissue, subpleural fibrosis, and accumulation of abnormal elastin fibers. Despite surfactant appearing abnormal by electron microscopy, the surface tension-lowering ability of the surfactant is normal. The changes in $\mathrm{G}$ and $\mathrm{H}$ can be explained by the progressive tissue destruction seen with age. However, the normal values of $\eta$ and the lack of changes with age despite progressive tissue destruction cannot. Although normal values of $\eta$ could be maintained if tissue destruction resulted in balanced changes in the dissipative and elastic properties of lung tissue, this would seem to be extremely unlikely. A more likely explanation is that $\eta$ is determined in vivo by a combination of the mechanical properties of fiber network and the surface-acting forces. Data from the present study are consistent with surface-acting forces being a greater determinant of $\eta$, when measured in whole animals in vivo at an end-expiratory pressure of $2 \mathrm{hPa}$, than are the mechanical properties of the fiber network. 


\section{CONCLUSION}

In summary, the results of the present study have shown that progressive abnormalities are seen in the mechanical properties of airways and lung tissues of animals deficient in SP-D. These changes are likely to be explained by the changes in lung structure and in lung volume seen in these animals and may give some clues as to the relative contributions of lung structural integrity and surface-acting forces to measurements of lung parenchymal mechanics in vivo in intact animals.

\section{REFERENCES}

1. Wert SE, Yoshida M, LeVine AM, Ikegami M, Jones T, Ross GF, Fisher JH, Korfhagen TR, Whitsett JA 2000 Increased metalloproteinase activity, oxidant production, and emphysema in surfactant protein D gene-inactivated mice. Proc Natl Acad Sci U S A 97:5972-5977

2. Wong CJ, Akiyama J, Allen L, Hawgood S 1996 Localization and developmental expression of surfactant proteins D and A in the respiratory tract of the mouse. Pediatr Res 39:930-937

3. Motwani M, White RA, Guo N, Dowler LL, Tauber AI, Sastry KN 1995 Mouse surfactant protein-D. cDNA cloning, characterization, and gene localization to chromosome 14. J Immunol 155:5671-5677

4. Wright JR 1997 Immunomodulatory functions of surfactant. Physiol Rev 77:931-962

5. Korfhagen TR, Sheftelyevich V, Burhans MS, Bruno MD, Ross GF, Wert SE, Stahlman MT, Jobe AH, Ikegami M, Whitsett JA, Fisher JH 1998 Surfactant protein-D regulates surfactant phospholipid homeostasis in vivo. J Biol Chem 273:28438-28443
6. Ikegami M, Whitsett JA, Jobe AJ, Ross G, Fisher J, Korfhagen T 2000 Surfactant metabolism in SP-D gene ablated mice. Am J Physiol 279:L468-L476

7. Hantos Z, Daroczy B, Suki B, Nagy S, Fredberg JJ 1992 Input impedance and peripheral inhomogeneity of dog lungs. J Appl Physiol 72:168-178

8. Sly PD, Hayden MJ, Petak F, Hantos Z 1996 Measurement of low-frequency respiratory impedance in infants. Am J Respir Crit Care Med 154:161-166

9. Fredberg JJ, Stamenovic D 1989 On the imperfect elasticity of lung tissue. J Appl Physiol 67:2408-2419

10. Schuessler TF, Bates JHT 1995 A computer-controlled research ventilator for small animals: design and evaluation. IEEE Trans Biomed Eng 42:860-866

11. Tomioka S, Bates JHT, Irvin CG 2002 Airway and tissue mechanics in a murine model of asthma: alveolar capsule vs. forced oscillations. J Appl Physiol 93:263-270

12. Weibel ER 1986 Functional morphology of lung parenchyma. In: Fishman AP (ed) Handbook of Physiology: The Respiratory System, Vol III. American Physiological Society, Bethesda, MD, pp 89-112

13. Petak F, Hall GL, Sly PD 1998 Repeated measurements of airway and parenchymal mechanics in rats by using low frequency forced oscillations. J Appl Physiol $84: 1680-1696$

14. Nagase T, Ludwig MS 1998 Antigen-induced responses in lung parenchymal strips during sinusoidal oscillation. Can J Physiol Pharmacol 76:176-181

15. Hantos Z, Petak F, Adamicza A, Daroczy B, Fredberg JJ 1995 Differential responses of global airway, terminal airway, and tissue impedances to histamine. J Appl Physiol 79:1440-1448

16. Petak F, Hantos Z, Adamicza A, Asztalos T, Sly PD 1997 Methacholine-induced bronchoconstriction in rats: effects of intravenous vs. aerosol delivery. J Appl Physiol 82:1479-1787

17. Glasser SW, Burhans MS, Korfhagen TR, Na CL, Sly PD, Ross GF, Ikegami M, Whitsett JA 2001 Altered stability of surfactant in SP-C-deficient mice. Proc Nat Acad Sci USA 98:6366-6371

18. Goerke J, Clements JA 1986 Alveolar surface tension and lung surfactant. In: Fishman AP (ed) Handbook of Physiology: The Respiratory System, Vol III. American Physiological Society, Bethesda, MD, pp 247-262 